\title{
Extração da lectina da folha de mandioca (Manihot esculenta Crantz) e o efeito de cátions divalentes na atividade hemaglutinante
}

\author{
Extraction of the lectin of cassava leaves(Manihot esculenta Crantz) \\ and the effect of divalent cations on the hemagglutinating activity
}

\author{
Maria Cristina SILVA ${ }^{2 *}$, Angelita Duarte CORRÊA ${ }^{1}$, Custódio Donizete dos SANTOS ${ }^{1}$, \\ Flávia Cristina Almeida MARCOS${ }^{1}$, Celeste Maria Patto de ABREU ${ }^{1}$
}

\begin{abstract}
Resumo
Lectinas são proteínas ligantes de carboidratos, capazes de aglutinar eritrócitos, podendo exercer ação antinutricional. O isolamento destas proteínas tóxicas é interessante tanto pela sua ação antinutricional, como pela sua aplicação em biotecnologia. Algumas lectinas necessitam da presença de íons divalentes para exercer sua atividade hemaglutinante (AH). O objetivo neste trabalho foi estudar diferentes métodos de extração da lectina da farinha de folhas de mandioca (FFM) e avaliar o efeito dos íons $\mathrm{Ca}^{2+}$ e $\mathrm{Mn}^{2+}$ para sua $\mathrm{AH}$. Foram feitos testes de extração das proteínas utilizando dois extratores, água e solução salina ( 0,15 mol.L-1 $, \mathrm{pH} 7,4)$, em quatro tempos de extração, 15, 60, 120 e 180 minutos. Para avaliar o efeito dos íons $\mathrm{Ca}^{2+}$ e $\mathrm{Mn}^{2+}$ na $\mathrm{AH}$ da lectina da FFM, o extrato proteico foi dialisado contra EDTA e a AH determinada. O efeito desses cátions na aglutinação de hemácias também foi avaliado isoladamente. O método de extração proteica usando água destilada como extrator por 15 minutos é o mais adequado. Não houve perda da $\mathrm{AH}$ na ausência dos íons. Os cátions $\mathrm{Ca}^{2+}\left(5 \mathrm{mmol}^{2} \mathrm{~L}^{-1}\right), \mathrm{Mn}^{2+}(1,3 \mathrm{e}$ 5 mmol.L $\mathrm{L}^{-1}$ ) e a mistura de ambos nas mesmas concentrações provocam aglutinação de hemácias, na ausência de lectina.

Palavras-chave: folha de mandioca; rendimento proteico; atividade hemaglutinante; ion divalente.
\end{abstract}

\begin{abstract}
Lectins are carbohydrates binding proteins, capable of agglutinating erythrocytes, which can act as anti-nutritional factors. The isolation of these toxic proteins is interesting both for its anti- nutritional action and for its application in biotechnology. Some lectins need the presence of divalent ions to express hemagglutinating activity $(\mathrm{AH})$. The objective of this work was to investigate different methods of extracting lectins from cassava leaf flour (CLF) and to evaluate the effect of the ions $\mathrm{Ca}^{2+}$ and $\mathrm{Mn}^{2+}$ on the AH. Protein extraction tests were performed utilizing two extractors, water and saline solution $\left(0.15\right.$ mol. $\left.\mathrm{L}^{-1}, \mathrm{NaCl} \mathrm{pH} 7.4\right)$, under four extraction times, 15, 60, 120, and 180 minutes. To evaluate the effect of the ions $\mathrm{Ca}^{2+}$ and $\mathrm{Mn}^{2+}$ on the $\mathrm{AH}$ of CLF lectin, the protein extract was dialyzed against EDTA and the AH was determined. The effect of the cations upon the agglutination of red blood cells was also evaluated individually. The protein extraction method utilizing water as extractor under 15 minutes was the most suitable. No loss of $\mathrm{AH}$ was found in the absence of the ions. The cations $\mathrm{Ca}^{2+}$ ( $\left.5 \mathrm{mmol} . \mathrm{L}^{-1}\right), \mathrm{Mn}^{2+}\left(1,3\right.$ and $\left.5 \mathrm{mmol} . \mathrm{L}^{-1}\right)$, and the mixture of both under the same concentrations provoked agglutination of red blood cells in the absence of lectin.
\end{abstract}

Keywords: cassava leaf; protein yield; hemagglutinating activity; divalent ion.

\section{Introdução}

A farinha de folhas de mandioca (FFM) é um dos constituintes da "multimistura" (produto composto de alimentos não convencionais), apresentando alto teor em proteínas, vitaminas e minerais. Todavia, elas também apresentam algumas substâncias consideradas antinutritivas e/ou tóxicas, como cianeto, polifenóis, nitrato, ácido oxálico, saponinas, inibidores de tripsina e as lectinas.

As técnicas de processamento usadas para preparar as folhas de mandioca, destinadas ao consumo humano, são capazes de eliminar em sua maioria, os fatores antinutricionais presentes. De acordo com Salles (1996), a desidratação é um dos procedimentos mais empregados para o processamento das folhas de mandioca, tendo como principal objetivo a destruição de micro-organismos, inativação de enzimas e fatores antinutricionais e melhoria na digestibilidade. Na desidratação em geral, utilizam-se dois fatores, a temperatura e a circulação de ar (CEREDA, 1996).

Lectinas são proteínas que reconhecem e se associam de forma reversível, com alta afinidade e especificidade a carboidratos, sem, contudo, apresentarem atividade enzimática (GABIUS et al., 2002; LORIS, 2002; PEUMANS; van DAMME, 1995). Algumas são classificadas como metaloproteína, pois necessitam de cátions como $\mathrm{Ca}^{2+}$ e $\mathrm{Mn}^{2+}$ para realizar a sua atividade hemaglutinante, sendo que estes íons estão associados a uma série de aminoácidos que participam da ligação ao carboidrato (MOREIRA et al., 1990, MURDOCK; SHADE, 2002).

${ }^{1}$ Departamento de Química, Universidade Federal de Lavras - UFLA, CEP 37200-000, Lavras - MG, Brasil, E-mail: crisiria@yahoo.com.br

${ }^{*}$ A quem a correspondência deve ser enviada 
Quando ingeridas, as lectinas não são degradadas durante sua passagem pelo trato digestivo e podem reconhecer resíduos de carboidratos presentes nas células intestinais, ligando-se a eles. Essa ligação às células das microvilosidades intestinais provoca interferência na absorção e utilização de nutrientes, levando a uma rápida perda de peso e inibição do crescimento de animais experimentais. Além dos efeitos degenerativos nas membranas celulares, as lectinas mostraram a capacidade de inibir várias enzimas intestinais (VASCONCELOS; OLIVEIRA, 2004).

A eliminação dos efeitos tóxicos das lectinas é realizada através de sua desnaturação por tratamento térmico úmido, uma vez que o calor seco é pouco efetivo (AREGHEORE et al., 1998).

Apesar de seus possíveis efeitos deletérios, elas podem ser utilizadas em diferentes áreas biológicas e médicas, devido à sua especificidade com relação aos diferentes carboidratos, como por exemplo: (1) na investigação de estrutura de proteína e carboidratos em células (SILVA, M. R.; SILVA M. A. A. P., 2000); (2) na utilização em matrizes comerciais de afinidade, empregadas na purificação e caracterização de polissacarídeos e glicoconjugados (LIMA et al., 1997); (3) na caracterização de grupos sanguíneos (LIS; SHARON, 1998); (4) na estimulação da mitogênese de linfócitos, abrindo novas perspectivas no campo da imunologia (SHARON; LIS, 2004); (5) na aglutinação de células cancerígenas, sendo utilizadas nos estudos de oncogênese (SHARON; LIS, 2004); e (6) como agentes defensivos na agricultura, em função de sua ação fungicida, bactericida e inseticida (GAIDAMASHVILI; van STADEN, 2002; PEUMANS Et al., 2000).

A busca de produtos naturais, que possam apresentar aplicações biotecnológicas, como as citadas acima, é extremamente relevante. Assim, estudar o potencial da lectina da folha de mandioca poderá agregar valor ao que antes era considerado um subproduto agrícola, além de gerar benefícios econômicos e contribuir para o meio ambiente, uma vez que milhares de toneladas de folhas de mandioca deixariam de ser descartadas, para serem utilizadas como suplemento alimentar e/ou em biotecnologia.

Pereira (2007) iniciou os estudos com a lectina de folhas de mandioca (Manihot esculenta Crantz cv. Cacao, aos 12 meses de idade). Nesse estudo, as proteínas da FFM foram extraídas empregando-se dois extratores, água destilada e solução salina tamponada $\left(\mathrm{NaCl} 0,15\right.$ mol.L $\mathrm{L}^{-1}, \mathrm{pH}$ 7,4) em três proporções: $1: 10,1: 15$ e $1: 20(\mathrm{~m} / \mathrm{v})$, durante 3 horas. O autor obteve maior rendimento de extração proteica $\left(0,99 \mathrm{~g} \cdot 100 \mathrm{~g}^{-1}\right)$ e maior $\mathrm{AH}$ (4 UH) utilizando água destilada na proporção 1:20 (m/v). Além disso, ainda nesse trabalho, após a precipitação proteica e purificação da lectina da FFM, não foi detectada atividade hemaglutinante $(\mathrm{AH})$, sendo restaurada apenas após a adição de extrato proteico fervido, sugerindo que, após a purificação, algum fator importante para a $\mathrm{AH}$ havia sido perdido.

De acordo com esses resultados, torna-se necessário investigar outros métodos de extração das proteínas da folha de mandioca no intuito de melhorar o rendimento proteico, mas, sobretudo, que contenha proteínas com maior $\mathrm{AH}$, bem como avaliar a dependência ou não de cátions divalentes para a $\mathrm{AH}$ da lectina da FFM.

Portanto o objetivo neste trabalho foi avaliar diferentes métodos de extração da lectina da FFM e avaliar a influência dos íons $\mathrm{Ca}^{2+}$ e $\mathrm{Mn}^{2+}$ para a sua atividade hemaglutinante (AH).

\section{Material e métodos}

\subsection{Preparo da farinha de folhas de mandioca}

Folhas maduras de mandioca (Manihot esculenta Crantz), cultivar Cacao, foram colhidas aos 12 meses de idade da planta. As folhas foram lavadas e secas em estufa ventilada à temperatura de 30 a $35^{\circ} \mathrm{C}$. Os pecíolos foram retirados após 24 horas de secagem e permaneceram na estufa por mais 24 horas. Em seguida, as folhas foram passadas em moinho tipo Willy para obtenção da farinha.

\subsection{Métodos de extração das proteínas}

Para escolher o método de extração das proteínas da farinha de folhas de mandioca (FFM) que proporcionasse maior quantidade de proteína e maior atividade hemaglutinante, foram testados dois extratores: água destilada e solução salina tamponada $\left(\mathrm{NaCl} 0,15\right.$ mol.L $\mathrm{L}^{-1}$, tampão fosfato $\mathrm{Na}_{2} \mathrm{HPO}_{4}$ 0,0309 mol.L $\mathrm{L}^{-1}, \mathrm{KH}_{2} \mathrm{PO}_{4} 0,0077$ mol.L $\mathrm{L}^{-1} \mathrm{pH}$ 7,4).

A proporção de FFM e extrator foi de 1:20 (m/v), de acordo com Pereira (2007). A mistura foi colocada sob agitação mecânica por quatro tempos de 15, 60, 120 e 180 minutos em temperatura ambiente. Em seguida, a suspensão foi filtrada em tecido de organza e centrifugada a $8.000 \mathrm{x} \mathrm{g}$, por 15 minutos a $7^{\circ} \mathrm{C}$ e o sobrenadante recolhido. O resíduo obtido foi submetido a duas reextrações sucessivas nas mesmas condições e os sobrenadantes (extrato) foram reunidos para determinação do teor proteico, atividade hemaglutinante e o efeito dos íons $\mathrm{Ca}^{+2}$

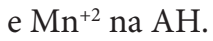

O delineamento experimental adotado foi inteiramente casualizado com três repetições, compondo um esquema fatorial $2 \times 4$, em que se avaliou a utilização de dois extratores, água destilada e solução salina tamponada, e o tempo de extração (15, 60, 120 e 180 minutos). As variáveis analisadas foram rendimento proteico e atividade hemaglutinante no extrato proteico. Os resultados observados para o rendimento proteico foram submetidos à análise de variância. Para o estudo das médias foram realizados o teste de Tukey e a análise de regressão.

\subsection{Dosagem de proteínas}

A determinação de proteínas foi realizada segundo a metodologia descrita por Bradford (1976), usando albumina sérica bovina como padrão.

\subsection{Determinação da atividade hemaglutinante}

A AH foi realizada segundo a metodologia descrita por Calderón de la Barca, Ochoa e Valencia (1985), usando placas 
de microtitulação contendo 8 fileiras de 12 poços cada, os quais foram preenchidos com $100 \mu \mathrm{L}$ de solução salina tamponada e em seguida acrescidos com igual volume de amostra nos primeiros poços da fileira. A amostra foi submetida a uma série de diluições na base $2\left(2^{0}, 2^{1}, 2^{2}, 2^{3}\right.$, etc.), em triplicata, com homogeneização e transferência de $100 \mu \mathrm{L}$ para o poço seguinte até o penúltimo poço da fila. Em seguida, a amostra diluída foi incubada com $100 \mu \mathrm{L}$ de suspensão de hemácias a $2 \%$, preparada com sangue humano tipo $\mathrm{A} \mathrm{Rh}$ positivo, em temperatura ambiente.

Foram realizadas leituras da aglutinação das hemácias visualmente, após 60 e 90 minutos. Os resultados foram expressos em número de unidades hemaglutinantes (UH), que é calculado a partir do inverso do título da maior diluição que ainda apresentou aglutinação visível. Por exemplo: considerando uma diluição $2^{2}$, o seu título igual a $1 / 4$ e o volume de amostra utilizado no ensaio de $100 \mu \mathrm{L}$, define-se que a atividade hemaglutinante será de $4 \mathrm{UH} .100 \mu \mathrm{L}^{-1}$. Os poços que continham somente a suspensão de eritrócitos serviram como controle.

\subsection{Efeito de cátions divalentes $\left(\mathrm{Ca}^{2+} e \mathrm{Mn}^{2+}\right)$ na atividade hemaglutinante}

Para a verificação do efeito dos cátions $\mathrm{Ca}^{+2} \mathrm{e} \mathrm{Mn}^{+2}$ sobre a $\mathrm{AH}$, o extrato proteico obtido da FFM foi dialisado contra EDTA 0,2 mol.L $\mathrm{L}^{-1}, \mathrm{pH}$ 10, por 48 horas, com 3 trocas diárias, seguidas de diálise contra $\mathrm{NaCl} 0,15 \mathrm{~mol} . \mathrm{L}^{-1}$ por 24 horas e usado para o ensaio da AH. Como controle utilizou-se o extrato proteico não dialisado contra EDTA.

O efeito desses cátions divalentes na aglutinação de hemácias também foi avaliado isoladamente. Para isso, incubouse $100 \mu \mathrm{L}$ de uma suspensão de eritrócitos a $2 \%$ com $100 \mu \mathrm{L}$ das seguintes soluções: solução salina $0,15 \mathrm{~mol} . \mathrm{L}^{-1}$, contendo $\mathrm{CaCl}_{2}$ nas concentrações de 1,3 e $5 \mathrm{mmol} . \mathrm{L}^{-1}$; solução salina 0,15 mol. $\mathrm{L}^{-1}$, contendo $\mathrm{MnCl}_{2}$ nas concentrações de 1,3 e $5 \mathrm{mmol} . \mathrm{L}^{-1}$; solução salina $0,15 \mathrm{~mol} \cdot \mathrm{L}^{-1}$, contendo $\mathrm{CaCl}_{2} \mathrm{e}$ $\mathrm{MnCl}_{2}$ nas concentrações de 1, 3 e $5 \mathrm{mmol} . \mathrm{L}^{-1}$. Como controle, utilizou-se $100 \mu \mathrm{L}$ da suspensão de eritrócitos $2 \%$ e $100 \mu \mathrm{L}$ de solução salina. A aglutinação das hemácias foi avaliada após 60 minutos de incubação.

\section{Resultados e discussões}

\subsection{Métodos de extração das proteínas}

A análise de variância para o rendimento proteico de extração mostrou efeito altamente significativo $(p \leq 0,01)$ para o tempo e para o extrator, havendo também interação significativa entre esses dois fatores. Diante deste resultado fez-se o desdobramento de tempo dentro de cada extrator e, em seguida, foi feito o desdobramento do extrator dentro de cada tempo.

A análise de regressão detectou aumento linear no rendimento proteico com o aumento do tempo de extração, quando o extrator utilizado foi a solução salina. No entanto, quando o extrator utilizado foi a água destilada, houve um decréscimo do rendimento proteico em um intervalo de extração compreendido entre 15 e aproximadamente 79 minutos. A partir deste ponto, o rendimento começou a aumentar com o aumento do tempo de extração (Figura 1).

$\mathrm{Na}$ Tabela 1, estão apresentados os rendimentos médios da extração das proteínas considerando-se os extratores utilizados. Para o tempo de extração de quinze minutos, não houve diferença significativa, pelo teste de Tukey, entre os dois extratores utilizados. Para os demais tempos de extração, a solução salina proporcionou maior extratibilidade proteica, o que está intimamente ligado ao aumento da força iônica do meio e o consequente aumento da solubilidade das proteínas.

As AH obtidas para cada tratamento estão apresentadas na Tabela 2. A água destilada com um tempo de extração de 15 minutos apresentou maior $\mathrm{AH}$.

Pereira (2007), extraindo as proteínas da FFM (Manihot esculenta Crantz, cv. Cacao, aos 12 meses de idade) com água destilada, por 180 minutos, obteve a maior $\mathrm{AH}$ (4 UH), com um rendimento de extração de 0,99 g.100 g-1. Portanto, verifica-se que no presente trabalho houve um aumento de $100 \%$ na $\mathrm{AH}(8 \mathrm{UH})$ com o tempo de extração de apenas 15 minutos, todavia um menor rendimento de extração proteica $\left(0,64 \mathrm{~g} \cdot 100 \mathrm{~g}^{-1}\right)$.

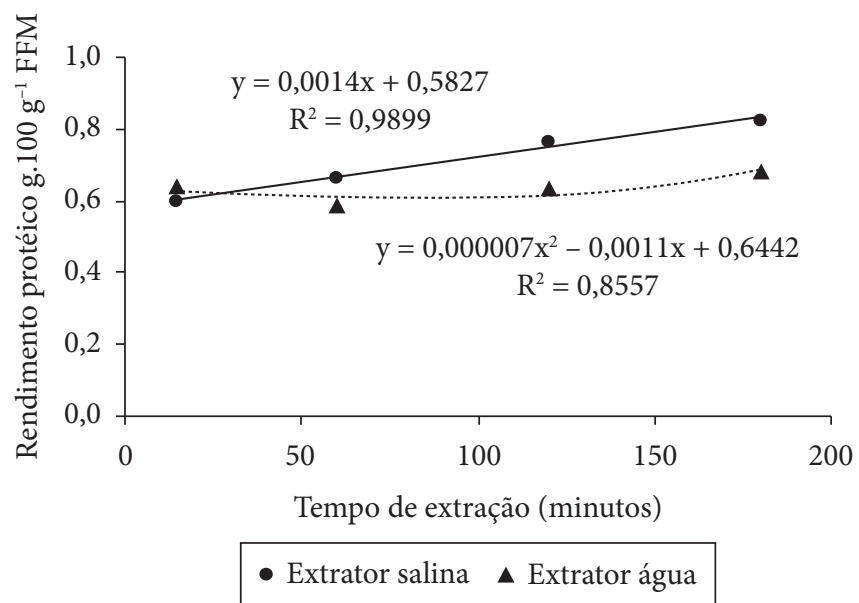

Figura 1. Curvas e equações de regressão representativas dos valores de rendimento protéico de dois extratores em função do tempo de extração.

Tabela 1. Rendimentos médios de proteína $\left(\mathrm{g} \cdot 100 \mathrm{~g}^{-1}\right)$ da farinha de folhas de mandioca.

\begin{tabular}{lcccc}
\hline & \multicolumn{5}{c}{ Tempo de extração (minutos) } \\
\hline \multicolumn{1}{c}{ Extrator } & 15 & 60 & 120 & 180 \\
\hline Água destilada & $0,64^{\mathrm{a}}$ & $0,59^{\mathrm{a}}$ & $0,63^{\mathrm{a}}$ & $0,68^{\mathrm{a}}$ \\
Solução salina $^{*}$ & $0,60^{\mathrm{a}}$ & $0,66^{\mathrm{b}}$ & $0,76^{\mathrm{b}}$ & $0,82^{\mathrm{b}}$ \\
Coeficiente variação (\%) & \multicolumn{4}{c}{4,93} \\
\hline
\end{tabular}

Médias seguidas da mesma letra na coluna não diferem entre si, pelo teste de Tukey, a 5\% de probabilidade; e *Solução de $\mathrm{NaCl} 0,15 \mathrm{~mol} . \mathrm{L}^{-1}$ com tampão fosfato $\mathrm{Na}_{2} \mathrm{HPO}_{4} 0,0309$ mol.L ${ }^{-1}, \mathrm{KH}_{2} \mathrm{PO}_{4} 0,0077$ mol.L ${ }^{-1} \mathrm{pH} 7,4$. 
Tabela 2. Atividade hemaglutinante com dois extratores e vários tempos de extração.

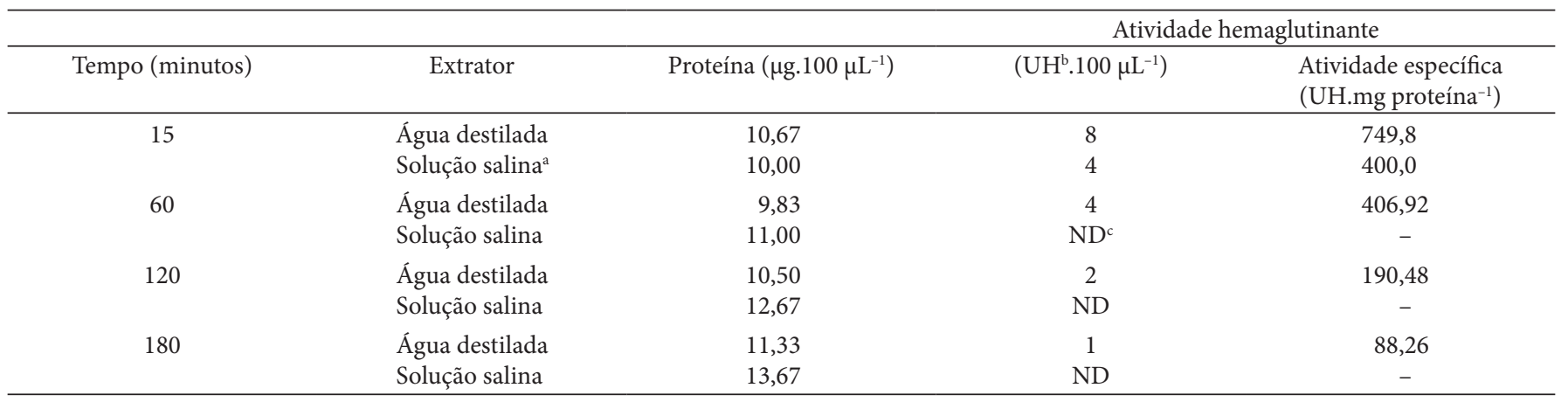

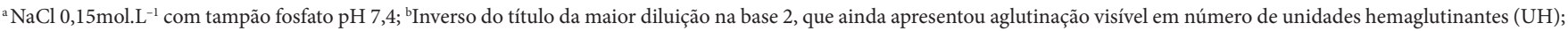
$\mathrm{e}^{\mathrm{c}}$ Não detectada.

\subsection{Efeito de cátions divalentes $\left(\mathrm{Ca}^{2+}\right.$ e $\left.\mathrm{Mn}^{2+}\right)$ na atividade hemaglutinante}

A fim de verificar se a lectina da FFM requer para a sua atividade os íons $\mathrm{Ca}^{2+}$ e $\mathrm{Mn}^{2+}$, o extrato proteico da FFM foi submetido à diálise contra EDTA (quelante de metais), $\mathrm{pH} 10$. Observou-se que não houve perda da $\mathrm{AH}$ após essa diálise. Este resultado sugere que a lectina da folha de mandioca parece não ser dependente dos cátions divalentes $\mathrm{Ca}^{2+}$ e $\mathrm{Mn}^{2+}$ para exercer sua $\mathrm{AH}$.

A lectina de sementes de Pouteria torta (BOLETI, 2003), quando incubada com ácido EDTA 0,025 mol. $\mathrm{L}^{-1}$ e ácido EGTA 0,025 mol. $\mathrm{L}^{-1}$, apresentou perda da atividade biológica, mostrando ser dependente de íons $\mathrm{Ca}^{2+}, \mathrm{Mn}^{2+}$ e $\mathrm{Mg}^{2+}$. No entanto, quando $\mathrm{Ca}^{2+}\left(12,5 \mathrm{mmol} . \mathrm{L}^{-1}\right)$ e $\mathrm{Mn}^{2+}\left(12,5 \mathrm{mmol} . \mathrm{L}^{-1}\right)$ foram adicionados ao ensaio de hemaglutinação, a atividade da lectina de Pouteria torta foi restaurada. Resultado semelhante pode ser observado para a lectina da esponja marinha Tedania ignis (DIAS, 2006), cuja atividade hemaglutinante no extrato bruto só foi detectada após a adição dos íons $\mathrm{Ca}^{2+}$ e $\mathrm{Mn}^{2+}$ na concentração de $25 \mathrm{mmol} \cdot \mathrm{L}^{-1}$.

Todavia, segundo Rüdiger (1998), cátions divalentes em altas concentrações são capazes de aglutinar células e, para garantir que a aglutinação está sendo mediada pela lectina, exige-se que ocorra a inibição dessa atividade com a adição de carboidratos. Por isto, a influência de íons $\mathrm{Ca}^{2+}$ e $\mathrm{Mn}^{2+}$ isoladamente na aglutinação de hemácias foi analisada e os resultados estão apresentados na Tabela 3. Verifica-se que, em todas as soluções salinas incubadas com uma suspensão de hemácias a $2 \%$, houve aglutinação destas células, exceto nas contendo 1 e 3 mmol. $\mathrm{L}^{-1}$ de $\mathrm{Ca}^{2+}$. Esse resultado confirma que os cátions $\mathrm{Ca}^{2+} \mathrm{e} \mathrm{Mn}^{2+}$ parecem exercer papel hemaglutinante e, quando adicionados ao ensaio de hemaglutinação, podem superestimar o valor desta atividade.

Diante dos resultados, torna-se necessário uma investigação mais detalhada sobre a real influência de cátions divalentes na atividade hemaglutinante de outras lectinas.
Tabela 3. Aglutinação de hemácias incubadas com soluções salinas contendo diferentes concentrações de $\mathrm{Ca}^{2+}$ e $\mathrm{Mn}^{2+}$ e da mistura de ambos os íons, na ausência de lectina.

\begin{tabular}{|c|c|}
\hline Soluções de $\mathrm{NaCl} 0,15$ mol.L ${ }^{-1}$ & Aglutinação de hemácias \\
\hline \multicolumn{2}{|c|}{ contendo $\mathrm{Ca}^{2+}$} \\
\hline $1 \mathrm{mmol} . \mathrm{L}^{-1}$ & negativo \\
\hline $3 \mathrm{mmol} . \mathrm{L}^{-1}$ & negativo \\
\hline $5 \mathrm{mmol} . \mathrm{L}^{-1}$ & positivo \\
\hline \multicolumn{2}{|c|}{ contendo $\mathrm{Mn}^{2+}$} \\
\hline $1 \mathrm{mmol} \cdot \mathrm{L}^{-1}$ & positivo \\
\hline $3 \mathrm{mmol} . \mathrm{L}^{-1}$ & positivo \\
\hline $5 \mathrm{mmol} . \mathrm{L}^{-1}$ & positivo \\
\hline \multicolumn{2}{|c|}{ contendo $\mathrm{Ca}^{2+} \mathrm{e} \mathrm{Mn}^{2+}$} \\
\hline $1 \mathrm{mmol} . \mathrm{L}^{-1}$ & positivo \\
\hline $3 \mathrm{mmol} . \mathrm{L}^{-1}$ & positivo \\
\hline $5 \mathrm{mmol} . \mathrm{L}^{-1}$ & positivo \\
\hline
\end{tabular}

\section{Conclusões}

Dos métodos de extração proteica estudados, aquele que usou água destilada como extrator por um tempo de 15 minutos é o mais adequado por que acarretou maior $\mathrm{AH}$, apesar de não ser o de maior rendimento de extração proteica.

A lectina da folha de mandioca parece não ser dependente de íons metálicos como $\mathrm{Ca}^{2+}$ e $\mathrm{Mn}^{2+}$ para exercer sua atividade hemaglutinante.

Os cátions $\mathrm{Ca}^{2+}\left(5 \mathrm{mmol} . \mathrm{L}^{-1}\right), \mathrm{Mn}^{2+}\left(1,3\right.$ e 5 mmol. $\left.\mathrm{L}^{-1}\right)$ e a mistura de ambos $\left(1,3\right.$ e $\left.5 \mathrm{mmol} . \mathrm{L}^{-1}\right)$ provocam a aglutinação de hemácias, portanto, cuidado deve ser tomado ao adicioná-los em ensaios de hemaglutinação.

\section{Agradecimentos}

À CAPES e ao CNPq pela bolsa de mestrado e de iniciação científica, respectivamente.

\section{Referências bibliográficas}

AREGHEORE, E. M.; MAKKAR, H. P. S.; BECKER, K. Assessment of lectin activity in a toxic and a non-toxic variety of Jatropha 
curcas latex agglutination and haemagglutination methods and inactivation of lectin by heat treatments. Journal of the Science of Food and Agriculture, v. 77, n. 3, p. 349-352, 1998.

BOLETI, A. P. A. Isolamento, caracterização físico-química e estudo da atividade inseticida e fungicida da lectina de sementes de Pouteria torta (Mart.) Radlk. Campinas, 2003. 98 p. Dissertação (Mestrado em Biologia Funcional e Molecular) - Universidade Estadual de Campinas - UNICAMP.

BRADFORD, M. M. A rapid and sensitive method for the quantitation of microgram quantites of protein utilizing the principle of proteindye binding. Analytical Biochemistry, v. 72, n. 1, p. 248-254, 1976.

CALDERÓN de la BARCA, A. M.; OCHOA, J. L.; VALENCIA, M. E. Effect of the extraction of a hemagglutinin on the nutritive value of Amaranthus leocarpus seeds. Journal of Food Science, v. 50, n. 6, p. 1700-1702, 1985.

CEREDA, M. P.; SURMELY, R. H.; ORTEGA-FLORES, C. Folhas de mandioca: verdades e mitos sobre sua potencialidade. Botucatu: UNESP, 1996. 31 p. (Relatório técnico científico).

DIAS, A. S. F. Lectina da esponja marinha Tedania ignis: purificação, caracterização e interação com leishmanias. Natal, 2006. 68 p. Dissertação (Mestrado em Bioquímica) - Universidade Federal do Rio Grande do Norte - UFRN.

GABIUS, H. J. Et al. The sugar code: functional lectinomics. Biochimica et Biophysica Acta - General Subjects, v. 1572, n. 2-3, p. 165-177, 2002.

GAIDAMASHVILI, M.; Van STADEN, J. Lectin-like proteins from South African plant species used in tradicional medicine. South African Journal of Botany, v. 68, p. 36-40, 2002.

LIMA, V. L. M. Et al. Immobilized Cratylia mollis lectin as a potential matrix to isolate plasma glycoproteins, including lecithincholesterol acyltranferase. Carbohydrate Polymers, v. 33, n. 1, p. 27-32, 1997.
LIS, H.; SHARON, N. Lectins: carbohydrates specific proteins that mediate cellular recognition. Chemical Reviews, v. 98, n. 2, p. 637-674, 1998.

LORIS, R. Principles of structures of animal and plant lectins. Biochimica et Biophysica Acta - General Subjects, v. 1572, n. 2-3, p. 198-208, 2002.

MOREIRA, R. A. Et al. Plant lectins: chemical and biological aspects. In: CONGRESS ON PROTEINS OF THE BRAZILIAN, 1., 1990, São Paulo. Proceedings... São Paulo: COBRAP, 1990. p. 73-96. (v. 90).

MURDOCK, L. L.; SHADE, R. E. Lectins and protease inhibitors as plant defenses against insects. Jounal of Agricultural and Food Chemistry, v. 50, n. 22, p. 6605-6611, 2002.

PEREIRA, C. A. Hemaglutinina de folhas de mandioca (Manihot esculenta Crantz): purificação parcial e toxicidade. Lavras, 2007. 43 p. Dissertação (Mestrado em Agroquímica) - Universidade Federal de Lavras - UFLA.

PEUMANS, W. J.; Van DAMME, E. J. M. Lectins as plant defense proteins. Plant Physiology, v. 109, n. 2, p. 347-352, 1995.

PEUMANS, W. J. Et al. Fruit-especific lectins from banana and plantain. Planta, v. 211, n. 6, p. 546-554, 2000.

RÜDIGER, H. Plant lectins-more than just tools for glicoscientists: occurrence, structure and possible functions of plant lectins. Acta Anatomica, v. 161, n. 1-4, p. 130-152, 1998.

SALLES, A. M. Processo de desidratação de alimentos e perdas antinutricionais. Botucatu: UNESP, 1996. (Relatório técnico científico)

SHARON, N.; LIS, H. History of lectins: from hemagglutinins to biological recognition molecules. Glycobiology, v. 14, n. 11, p. 53R-62R, 2004.

SILVA, M. R.; SILVA, M. A. A. P. fatores antinutricionais: inibidores de proteases e lectinas. Revista de Nutrição, v. 13, n. 1, p. 3-9, 2000.

VASCONCELOS, I. M.; OLIVEIRA, J. T. A. Antinutritional properties of plant lectins. Toxicon, v. 44, n. 4, p. 385-403, 2004. 